\title{
Media and Misinformation in Times of COVID-19: How People Informed Themselves in the Days Following the Portuguese Declaration of the State of Emergency
}

\author{
Gil Baptista Ferreira ${ }^{1, *}$ and Susana Borges $2, *$ (D) \\ 1 Labcom-Communication and Arts, Polytechnic Institute of Coimbra, Coimbra Education School, \\ 3030-329 Coimbra, Portugal \\ 2 Centre of 20th Century Interdisciplinary Studies (CEIS20), Polytechnic Institute of Coimbra, Coimbra \\ Education School, 3030-329 Coimbra, Portugal \\ * Correspondence: gbatista@esec.pt (G.B.F.); suborges@esec.pt (S.B.)
}

Received: 25 October 2020; Accepted: 25 November 2020; Published: 2 December 2020

\begin{abstract}
This study takes as a starting point the importance and dependence of the media to obtain information about the pandemic. The dependency theory of the media system was developed in the 1970s when mass media were the dominant source of information. Today, at a time when media choices have become abundant, studies are needed to understand the phenomenon of media dependence in light of new dimensions made important by the transformations that have taken place in the social and media fields-where the coexistence of mass media with social media platforms stands out. As large-scale crises rarely occur and the media environment changes rapidly, it is important to analyze how media dependence relates to choose and trust in different media (traditional media vs. social media) in times of crisis. Several questions arise. What is the trust attributed by individuals to social media as sources of information about COVID-19? How well informed are the individuals who choose these sources as the main sources of information? From a questionnaire administered to 244 individuals in Portugal, during the first week of the state of emergency (March 2020), this research seeks to identify how people gained access to information about COVID-19, how they acted critically towards the various sources and how they assess the reliability of different media. Finally, it analyzes the association between the type of medium chosen and adherence to misinformation content about the virus. The results reveal the existence of a phenomenon of dependence on the media, with a strong exposure (both active and accidental) to informative content, with conventional media being privileged as the main source, and positively distinguished in terms of confidence. Finally, a statistically significant association of a positive sign was identified between the use of social media as the main source and the acceptance of misinformation.
\end{abstract}

Keywords: COVID-19; information sources; misinformation; social media

\section{Introduction}

It is well known how informative media is a fundamental lens through which people see society and the world. Thanks to their reach and omnipresence, the individuals have now more opportunities to find news and information than ever before. In addition to traditional media, such as television, newspapers and radio, the circulation of news on the Internet and social networks offers people the possibility of being exposed to information, even if they do not purposely seek it out. Due to the growing supply, several studies have been listing factors that determine which media people consult, and the effects of privileged exposure to each of these media. 
At first glance, the abundance of information can be considered a favorable factor for obtaining better-informed citizens, especially since the volume and diversity of information in the media environment promote learning about the most relevant public issues (Barabas and Jerit 2009). In times of crisis, as are those in which large-scale natural disasters, terrorist attacks or disease outbreaks occur, the importance of this factor increases and information from the media becomes a key element for the functioning of society. Due to the high level of uncertainty, it is in the media that most people usually trust to understand the environment in which they live and make decisions regarding that environment. Similarly, in these situations, the media's influence is often amplified. Especially in crisis management situations, the use of reliable sources of information is one of the most important factors of social behavior (Longstaff 2005).

This study is about how individuals informed themselves about the COVID-19 pandemic in Portugal, in the days following the declaration of the state of emergency (18 March 2020). The rapid spread of the disease was accompanied by an equal surge of information through social and conventional media, allowing a vast torrent of "news" about the origins of the virus and ways to fight it to circulate as quickly as the infection. With the arrival and spread of COVID-19, Tedros Adhanom Ghebreyesus, the Director-General of the World Health Organization (WHO), claimed, in February 2020, "We're not just fighting an epidemic; we are fighting an infodemic" (World Health Organization 2020). In such a situation, people must have access to news and information that they trust and that can help them understanding, the various aspects related to the nature of the coronavirus (which is important to protect themselves), but also independent information on how governments and other officials respond to the pandemic (with decisive importance for the assessment of political action).

Unquestionably, both true information and the various types of wrong information (from inaccurate to purposely false information) shape the way people understand and respond to the ongoing public health crisis, as well as the assessment of how institutions are dealing with it. As has been known for a long time, it is risk perceptions (pseudo-environments, in Walter Lippman's terms), and not the real risk, that determine how people respond to crises (Glik 2007).

Traditionally, mass media such as television and newspapers, which carry information from authorized sources, played the role of transmitting official information. However, over the past few decades, the rise of the Internet, and in particular of social media, has substantially changed the media environment. Firstly, because these media challenge the role of the mass media, by providing effective channels to reach alternative sources of information (Castells 2007). Despite the very different nature of these two types of media (conventional media and social media), they are highly interconnected (Napoli 2019). Their combined and permanent use sustains and, to a large extent, deepens the dependence of individuals on the media system. As a whole, the vast volume of news and information surrounding COVID-19-the ambiguity, uncertainty and misleading nature, and sometimes the low quality, or the totally false nature of some of this information-justify the use by WHO of the term infodemic. In March of this year, Tedros Adhanom Ghebreyesus said, "At WHO, we are not only fighting the virus but also troll and conspiracy theorists who spread wrong information and hamper the response to the outbreak" (World Health Organization 2020). With the infodemic neologism, WHO wanted, in the days when the fear of the coronavirus spread, to point out another danger of societies in the age of social media: the distortion of reality in the buzz of echoes and comments both about real facts and about facts frequently invented (Cinelli et al. 2020). A US State Department study, initially published in The Washington Post (29 February 2020), reported that approximately 2 million tweets spread coronavirus conspiracy theories during the three weeks that the outbreak began to spread outside of China. Among the most common publications were those that described the virus as "a biological weapon". This and other false rumors represented $7 \%$ of the total tweets studied and were characterized as "potentially impacting on the most popular social media conversations", according to the report obtained by The Washington Post. It should be noted that the new coronavirus is, for practical purposes, identified by researchers as a single pathogen microorganism, properly diagnosed and tested, with its dissemination mapped. Nevertheless, we find that, in addition 
to the proven false misinformation, deliberately elaborated and manipulated, identified by fact checkers, much of what we learned about the new coronavirus remains difficult to separate clearly and cleanly in terms of information and disinformation, true and false, reliable and unreliable (Brennen et al. 2020). This perception leads the majority of the public to further emphasize the importance of the reliability of sources, whether they are professional media of information, public authorities or social media platforms (Nielsen and Graves 2017; Newman et al. 2017).

This study takes as a starting point the importance and dependence of the media (Ball-Rokeach and DeFleur 1976) to obtain information about the pandemic. Based on a questionnaire applied to a sample of 240 individuals, in Portugal, in the first week in which the state of emergency was in force, this research analyzes how people accessed information about COVID-19 and how they assessed the reliability of different sources and communication platforms. The type of relationship with information - the search for information or accidental exposure to information-will also be considered from the perspective of the quality of the information achieved. Finally, it analyzes the association between the type of medium to which they attributed greater confidence, and the adherence to content identified as misinformation about the pandemic.

\section{Literature Review}

\subsection{Dependence on the Media System}

We take as a framework some of the elements that characterize the theory of dependence on the media system (Ball-Rokeach and DeFleur 1976) because we believe that this model helps us to define the importance that media assume in a context like the present. In its most general features, this theoretical framework assumes that, in modern societies, people depend on the media for information and explanations about what is happening. We find this dependency in many everyday situations, from the need to find the best purchases in the supermarket to more general needs, such as obtaining the kind of information that allows maintaining connection and familiarity with the social world "outside the neighborhood". The greater the need and, consequently, the stronger the dependence, the greater the likelihood that the information provided will alter cognitions, feelings and behaviors. Now, as societies become more complex, and at a time when the quality of mediation technologies and the generalization of their use are expanding, the media assume themselves as the increasingly exclusive information mode, with the sacrifice in other more direct ways of reaching that information.

The dependency theory of the media system predicts that the dependence that people feel on the media tends to increase in crisis situations (Ball-Rokeach 1985). The initial works of this theory state two main factors that can affect the intensity and nature of the addiction: the level of ambiguity and the threat. This means that when important characteristics of the social environment become unpredictable and/or undecipherable (which occurs in crisis situations such as natural disasters or disease outbreaks), the dependence on the media increases, especially if they are perceived as the best or the main source of information available (Ball-Rokeach 1985). When the initial information provided by the media is incomplete, feelings of ambiguity occur, individuals know that an event has occurred, but they do not know what it means or how to interpret it. As a result, more information will be sought in an attempt to resolve this ambiguity—which increases the existing dependency.

This process of increasing dependency is described, among others, in studies focused on the terrorist attacks of 11 September 2001 (Lowrey 2004), in the 2009 N1H1 outbreak in China (Hu and Zhang 2014) or the earthquake 2008 in China (Jiang and Ouyang 2008). It is in the same category that the case of the present pandemic of COVID-19 fits-an outbreak with many uncertainties, in which scientists cannot give all the answers and guarantees, in which it is understandable that people are frightened and that the images of masks and large deserted cities cause more anxiety (Sahni and Sharma 2020). The limitation of ways of social interaction (confinement), another expression of the fight against the pandemic, also ends up increasing the power and centrality of the media. 
The theory of dependence on the media system was developed in the 1970s when the mass media were the dominant source of information. Almost half a century later, at a time when media choices have become abundant, studies are needed to understand the phenomenon of media dependence in light of new dimensions made important by the transformations that have taken place in the social and media fields-where the coexistence of mass media with social media platforms stands out. As large-scale crises rarely occur and the media environment changes rapidly, it is worth analyzing how media dependency relates to choice of, and trust in, different types of media (traditional media vs. social media) in times of crisis. The crisis situation caused by the COVID-19 pandemic has this particularity, insofar as it isolates individuals, it leads them to resort more and more to social media (without this necessarily implying less consumption of traditional media) to maintain a sense of social connection. However, exposure to these media, albeit casual, turned them into yet another source of information on the pandemic problem. If it is familiarity with the media that makes individuals more dependent on them, what the current crisis has amplified is the need to gauge the importance of social networks like Facebook or Twitter, not only as spaces for social interaction but still as essential sources of information.

It is from this perspective of analysis that this study arises, and from where it asks some questions. Concretely, what is the trust attributed by individuals to the different media, as sources of information about the pandemic? Does the search attitude or the mere exposure to accidental sources of information correspond in terms of the perception of reality? Is it possible to associate the sources to which individuals attribute trust with susceptibility to misinformation? Finally, the ongoing pandemic crisis will awaken society to old values associated with the ethos and the most classic functions of journalism-namely, the first and most confused of journalism's commitments-with the truth (Kovach and Rosentiel 2005).

\subsection{Information Search and Exposure}

In the current information ecosystem, "perception of the environment" is achieved, significantly, through mobile devices, from which individuals have access to a variety of information sources, ranging from notifications made by news companies to publications coming from ordinary individuals, with more or less personal relevance (Hermida 2010). Recent studies have suggested that the possibility of switching between traditional media and various online media, in addition to the role played by a network of "friends" in the selection of information, may have important implications for political behavior (Aldrich et al. 2016). While the abundance of media options can offer citizens more opportunities to take advantage of access to information, some researchers argue that a high-choice media environment can have negative effects, widening knowledge gaps according to the preferences, interests and patterns of use of the media. According to this perspective, individuals who seek and choose from the plethora of available news derive a greater benefit from accessing information, while those who do not actively seek information but are accidentally exposed to it will experience lower gains in knowledge, despite the volume of information in these environments (for example, Hopmann et al. 2016; Wei and Hindman 2011). To this extent, as attention to news moves from information media platforms to social media environments, it is noted that individuals show a lesser need to regularly follow traditional media. Instead, people increasingly depend on their extended networks of "friends" to get relevant news and information (Matsa and Shearer 2018).

In an environment like the current one, composed of multiple options, issues of public interest compete with an immense amount of content of other types-namely, entertainment. While those interested in information look for news and can become more avid consumers, those less interested will increasingly tend to avoid the news, choosing other types of media and content. Research conducted by Zúñiga and Diehl (2019) reveals, in this regard, that the more someone is exposed to information through their networks, the less likely they are to actively seek news-a trend that leads to the perception that this media environment will serve your information needs. To this extent, a paradoxical effect of this process will turn out to be an increasing growth in information differences between 
individuals (a new form of information gap). Less interested individuals will tend to avoid news (in the sense of hard news) on issues of public interest, at the same time that an increasing volume of in-depth information is reaching, above all, the most interested (Prior 2005). At the same time, as individuals find more and more news and information without specific effort, through social media platforms, they can create the perception of being well informed-according to an effect called "newws-finds-me" (NFM) (Zúñiga et al. 2017). Recent studies, based on this concept, suggest that high perceptions of NFM are negatively related to the acquisition of knowledge, interest and action (Zúñiga and Diehl 2019), despite the frequent consumption of information from the media.

Other research (for example, Shehata 2014) further suggests that those who do not actively seek news because they have a low level of interest and motivation are often influenced by more passive exposure to media content. The result of this exposure is very clear, and can be identified, by contrast, in the following conclusion: as predicted by virtuous circle theory, motivated news attention lowers cynicism and increases institutional trust as well as political interest (Shehata 2014). In other words, a higher motivation of individuals to search for information translates a greater interest in public affairs and is reflected in attitudes of greater confidence in institutions such as, among others, public institutions or professional media. Conversely, a more passive exposure, not motivated and accidental to information, will be associated with higher levels of cynicism and of mistrust associated with lack of interest in the classical social institutions-which also include, among others, political power or the media mainstream. To this extent, one of the relevant and challenging questions is whether the quality of information depends on individuals actively seeking information or whether people can be passively informed through accidental exposure (Hopmann et al. 2015).

\subsection{Trust in the Media}

The issues associated with trust are central to all human activities and are the basis of the social relationship that we designate as citizenship (Coleman 2012, p. 36). Over the past few decades, a series of transformations have put the concept of trust under pressure-namely globalization, digitalization and a growing focus on the individual vis à vis the community (Fisher 2016). In conceptual terms, several names have been proposed to characterize the most recent social change, "risk society" (Beck 1992) to "liquid modernity" (Bauman 2000), all demonstrating the fragility of the classical notion of trust. Among the most direct consequences of this period of instability is the emergence of a crisis of confidence in public, political and media institutions (Bogaerts and Carpentier 2013; Coleman 2012).

In this context, the levels of trust in the media also influence the way people access news. If a high degree of confidence has traditionally been inseparable from the use of traditional information sources, of which newspapers are the paradigm (Tsfati and Cappella 2003), today we are witnessing the emergence of an environment marked by widespread distrust and disinterest in information about public issues. Data from a study by Tsfati and Cappella (2005) show that people who trust mainstream media are distinguished from those who do not because they tend to consult and inform themselves; nevertheless, exposure to non-mainstream media is not significantly different on the part of the two groups of individuals. An explanation can be found in the fact that, for certain individuals, exposure to the media satisfies needs that remain, even when trust is alienated. Tsfati and Cappella (2005) explore the moderating role of the "need for cognition" in the association between trust and exposure to the media. They argue that for people with a high "need for cognition", the need to think, understand the world and comprehend various points of view motivates exposure to news, regardless of whether the media are perceived as reliable or not. The transfer of trust that individuals had in mainstream media to social media results in sporadic consumption of news (Molyneux 2018). Furthermore, politics is rarely a topic of centrality in social networks, and when it is, it is biased and partial (Bisgin et al. 2012). Without this regular exposure to news, individuals will be less able to identify relevant political information, and even less to translate that information into political interest.

In a context like the current one, with a media ecosystem that throughout recent years came to be plagued by progressive credibility crisis (of which the debate on fake news is perhaps the most 
strident symptom), the present pandemic emerges as an unprecedented challenge for journalism-to the point that it is identified as an antidote to the disinformation pandemic, understanding by this concept all false information, whether on purpose or not (Brennen et al. 2020). To a large extent, the extraordinary circumstances surrounding the present infodemic are seen as a giant "confidence test" of Western societies concerning the media. A recent survey by Edelman (2020) on confidence during COVID-19 shows that research on reliable information about the pandemic has motivated an increase in confidence in the news (Figure 1). Global confidence in the media rose by $5 \%$, with traditional media ( +7 points) and owned media ( +8 points) being the fastest growing media. Separately, the most reliable media are traditional media $(69 \%)$, followed by search engines $(64 \%)$. The aforementioned owned media (professional media), which in 2015 deserved less confidence than social media ( $41 \%$ vs. 44\%) are now, for the first time on this barometer, above $50 \%$, deserving higher confidence than the media ( $52 \%$ vs. $45 \%$ ). However, despite high levels of trust in news sources, the urgent need for credible and impartial journalism is highlighted. Concerns about fake news are high, with $67 \%$ of respondents concerned that false or erroneous information about COVID-19 may be being shared.

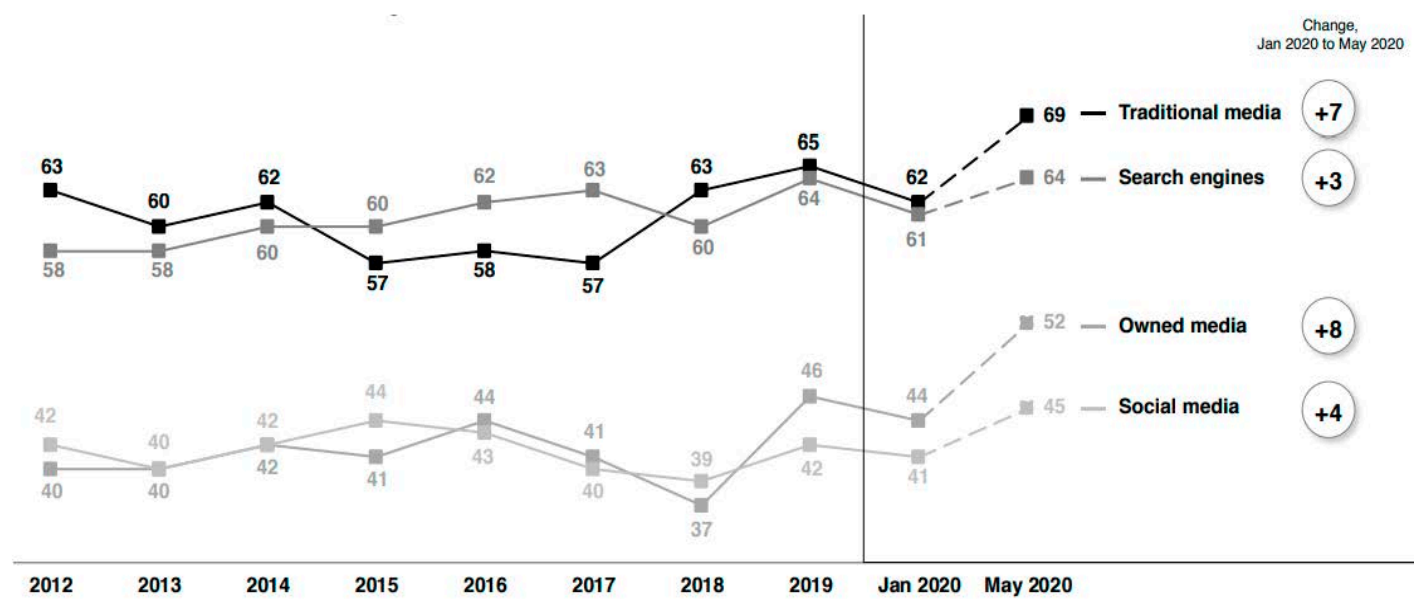

Figure 1. When looking for news and information, how much would you trust each type of news and information source? Source: Edelman Trust Barometer Spring Update.

\section{Hypotheses and Methodology}

With the previous theoretical and conceptual framework as a reference, and using the COVID-19 pandemic information theme as a topic of analysis, this article aims to investigate the relationship between people's dependence on the media system (encompassing conventional media) and social media, the choices they make within that system and some of the consequences that result from those options. We consider, for this purpose, the importance of variables as the primary medium of obtaining information (and in this case, if the primary medium used involves the active search or passive and accidental exposure to information) and the confidence (defined by the indication of the most reliable medium). Considering the aforementioned variables, the study aims to analyze adherence to forms of misinformation and conspiracy theories, confronting the individuals studied with some of the false news or rumors without proof or evidence that, regarding COVID-19, circulated more notoriously in the media environment.

We start from the premise that the studied individuals express feelings of dependence on the media concerning the COVID-19 pandemic. This premise will be supported from the observation of two conditions: the wide and recurring recourse to the different types of medium available (and not just those specifically informative or just those referred to as trustworthy) and the enhancement of the role of the media as a source of information about the problem.

From this premise, it is important to assess which are the most important sources for obtaining information about COVID-19. In a crisis situation, in which conventional media and social media coexist, interrelate, and are widely accessible, which media valued individuals to learn about the 
COVID-19 pandemic? In line with the most recent literature and research, although both types of media are widely consulted, it will be expected that traditional media will tend to be preferred as the main source of information about the COVID-19 pandemic over social media. Therefore, we formulated the following hypothesis:

Hypothesis 1 (H1). Individuals prefer traditional media over social media as the main source of information about the COVID-19 pandemic.

Following the previous hypothesis, and in close association with this, we consider the attribute of trust granted to each type of media. The choice of the main source will tend to be associated with the attribute of trust and to reveal a close distribution. Along the same lines, traditional media will tend to be indicated as more reliable as a source for the COVID-19 pandemic, compared to social media.

Hypothesis 2 (H2). Individuals rely more on traditional media than on social media as a source of information about the COVID-19 pandemic.

Another dimension to take into account is the quality of the information that reaches each individual, and the relationship they establish with their main source of information. We take as a reference the concept described above of NFM, which indicates that individuals who privilege specifically informative media (those who seek and choose from the infinity of news available) derive a greater benefit from accessing information. Conversely, those who do not actively seek information, but are exposed to it accidentally (namely in social media), will have lower gains in knowledge, despite the volume of information they consume. To this end, we consider that the quality of information is intrinsically related to an essential attribute: truth, as a condition of the quality of information and its first attribute. In this sense, we will analyze the existence (or not) of a dependency association between the source that individuals designated as the "principal" source of the main information about the COVID-19 pandemic and adherence to false news/rumors. The hypothesis that we will test is as follows:

Hypothesis 3 (H3). The acceptance of disinformation is associated with the source of information chosen as the main one.

From the submission of a questionnaire distributed and expanded following the snowball model, a non-probabilistic, convenience sample was obtained, composed of 244 individuals from Portugal, with a balanced distribution in terms of gender and age groups. The data were collected during the first week of the state of emergency (between 19 and 26 March 2020), and reveal information about the news/information sources on the COVID-19 pandemic, identifying which media are used, the main medium and the most reliable medium for each individual. Finally, having been suggested some of the main false theories about the COVD-19, the degree of acceptance of these same theories was questioned. The data were analyzed using elements of descriptive statistics, and tests of association of variables were carried out through contingency tables, performed with the IBM SPSS data analysis software.

\section{Results}

The first data we sought to obtain aimed at supporting (or refuting) the premise regarding the existence of feelings of dependence on individuals to the media system, concerning obtaining information about COVID-19. To that end, individuals were consulted about the various types of media they used as sources of information, and also about the extent to which they considered them to be valid-namely, questioning whether the information they transmit should be considered. The results support the proposed premise, by demonstrating that, clearly, the media assumed themselves as a practically exclusive mode of information. 
First, the data show that various types of media and platforms were used as a source of information on the pandemic. Not only the television (92\%) and digital newspapers (65\%) were extensively consulted in the week under review, but also social networks (65\%) and internet search engines (57\%) were accessed for information about the new coronavirus (Figure 2).

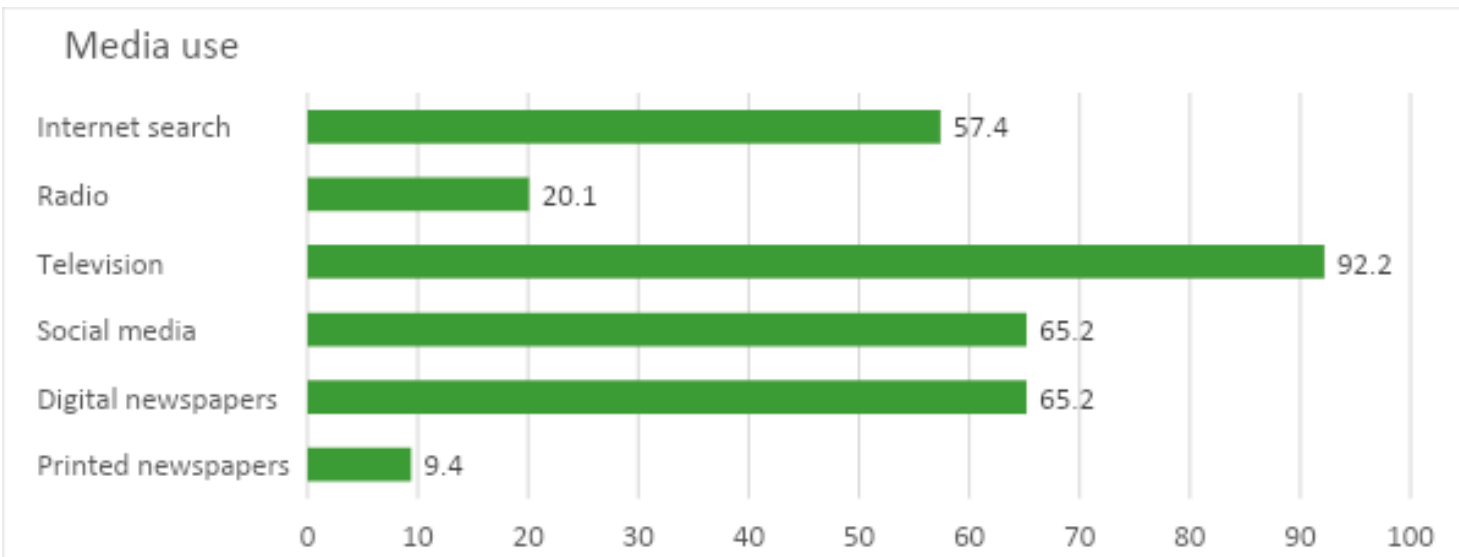

Figure 2. In the last week, concerning the COVID-19 pandemic, these sources of information used were used (\%).

Second, the importance and dependence of the media to obtain information about the COVID-19 pandemic are also supported in the answer to the question about whether "we should always see and hear the information that the media makes available to us." This question deserves the affirmative answer of $82 \%$ of the respondents, and the most chosen option was the one that represents a greater acceptance on the scale used, revealing the degree of importance attributed to the media (Figure 3).

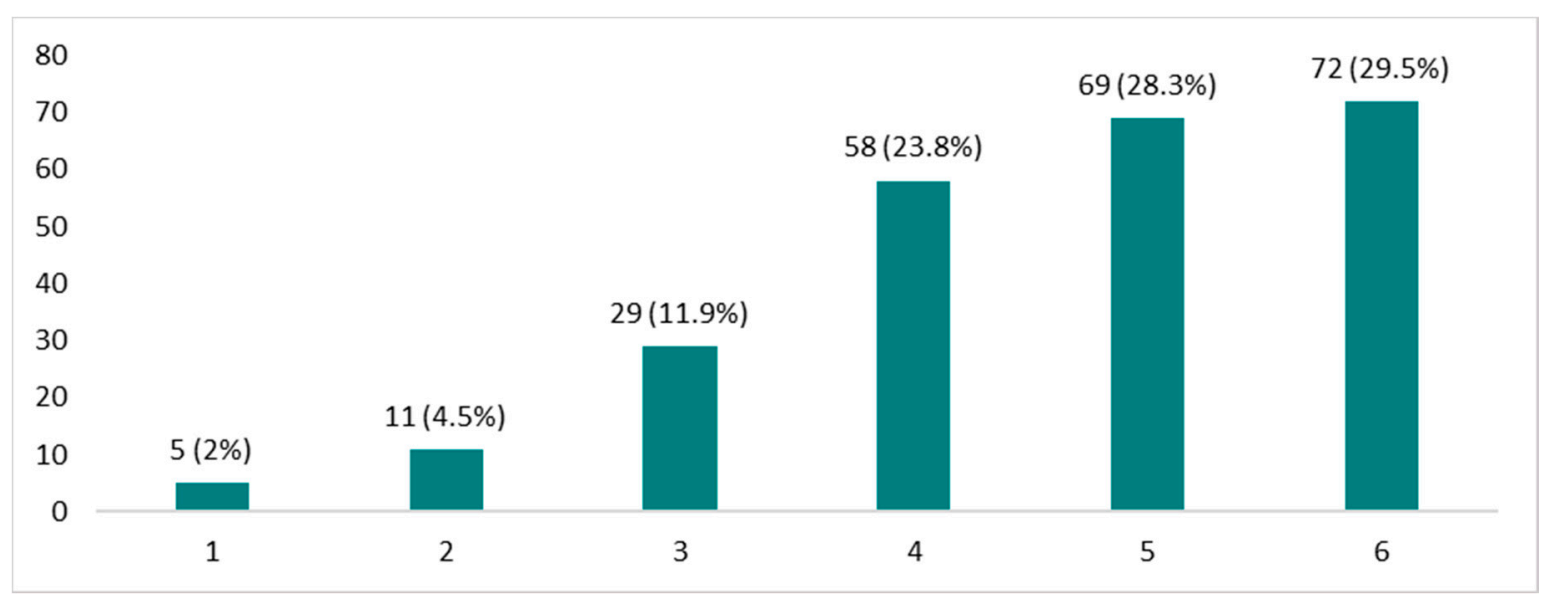

Figure 3. We should always see and hear information that the media make available to us. 1: strongly disagree; 6: strongly agree.

If we associate these responses with the period of social confinement then in force, which drastically reduced both interpersonal contact and other forms of direct knowledge of reality, we can consider as highly plausible the initial premise, which suggests the dependence of individuals on the media system.

Then, we tried to find out, in a context marked by the abundance of media supply and its accessibility, which is the "main source" of information about the COVID-19 pandemic. The results obtained are consistent with the expectations set out in previous research, and show that most people choose professional media of information as the main source of information about the pandemic - namely, television and newspapers (in digital versions and, less, on paper). In a different 
sense, social networks, used by $65 \%$ of individuals, are indicated as the main source of information by only $9 \%$ of respondents, half of those who choose digital newspapers as their main source and considerably less than those who are mainly informed by television (Figure 4).

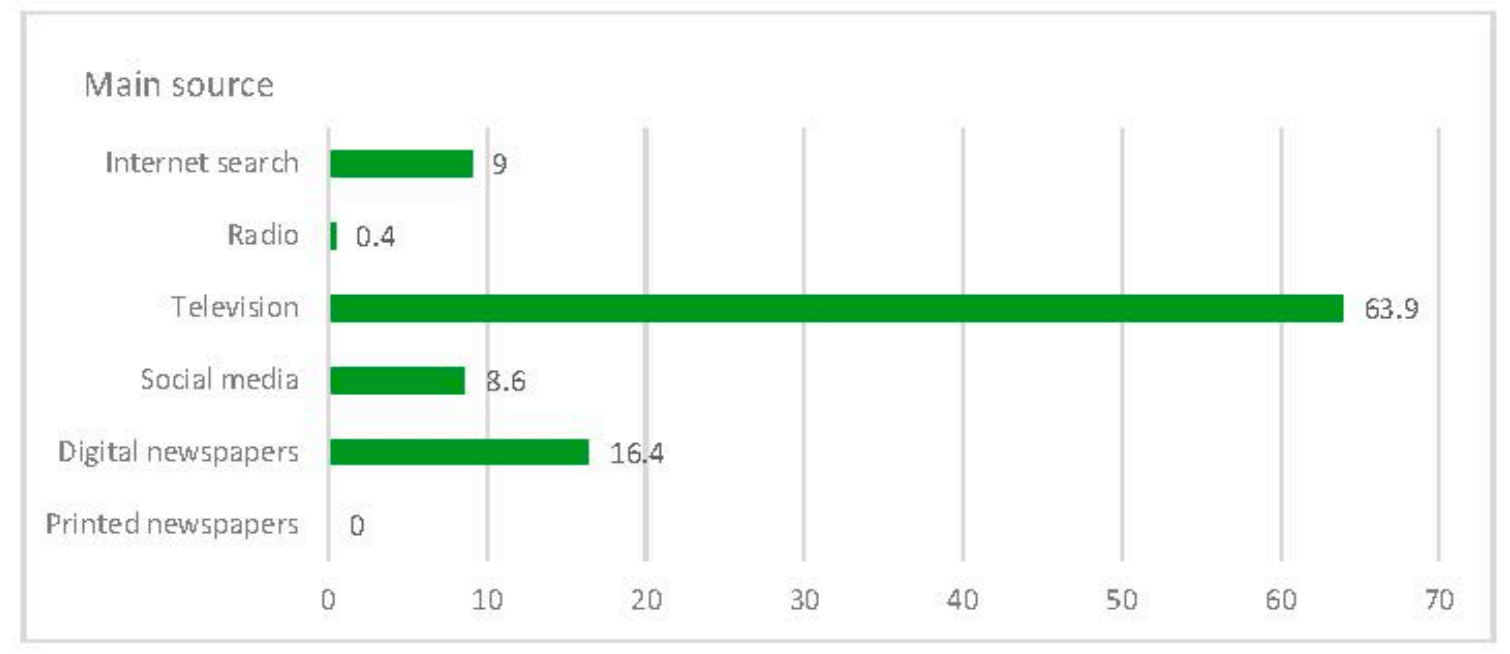

Figure 4. Among the media you used, which one do you consider as your main source for information about the COVID-19 pandemic during the last week (\%)?

Third, we went on to assess the trust in each of the media, asking which of the media consulted to obtain information about the pandemic deserved more confidence. By the obtained data, the majority of individuals expressed strong trust in news organizations for news and information about the coronavirus, whether television (65.2\%) or newspapers (print and digital, with $25.4 \%$ ). Conversely, social media platforms are referred to as less reliable, as they are marked as deserving greater trust by only $4 \%$ of the surveyed individuals (Figure 5).

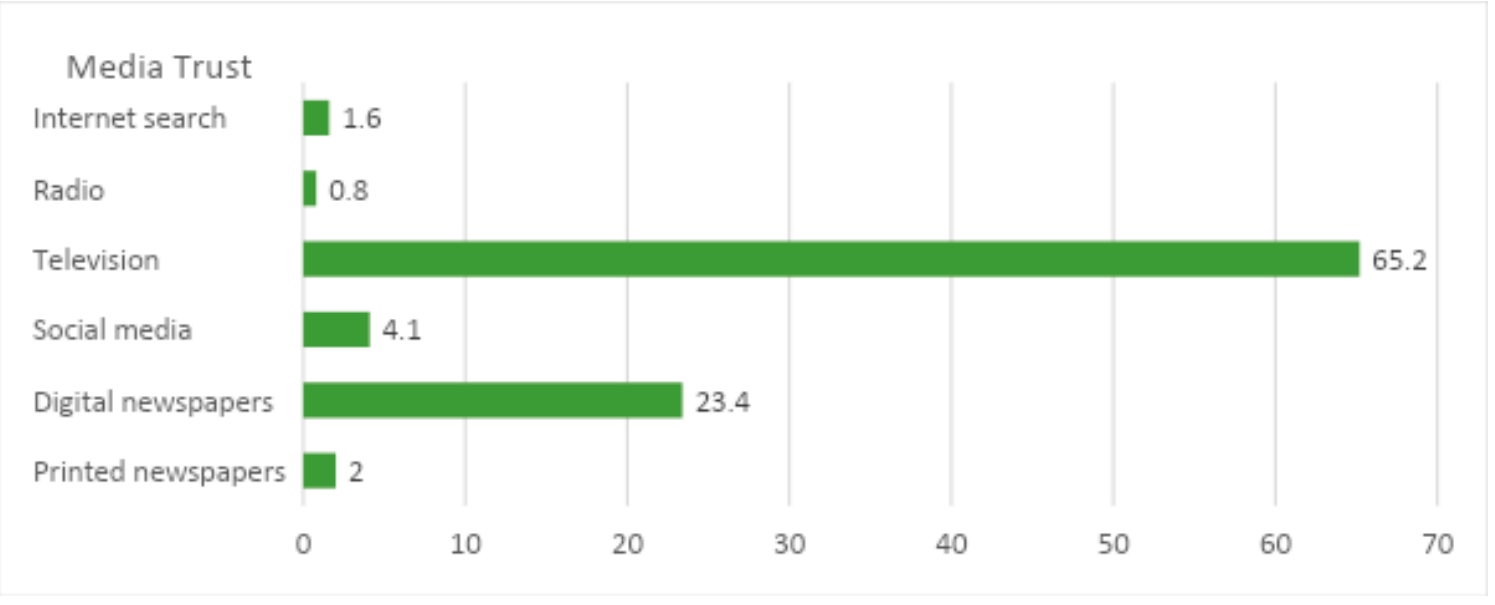

Figure 5. Regarding the COVID-19 pandemic, which medium did you trust most (\%)?

Finally, as a way of introducing the variable related to disinformation, we intend to assess the acceptance by the studied individuals of a proposition about COVID-19 widely disseminated through various media. Fuchs $(2020$, p. 392) enunciated, in a recent study, a list of "false news about coronaviruses"; from this list, we selected the story stated first, regarding the origin of the virus: "The coronavirus is a Chinese biological weapon developed at the Wuhan Institute of Technology." In our study, we sought to assess the degree of acceptance of this thesis by asking an equivalent question. The following data were obtained (Figure 6): 


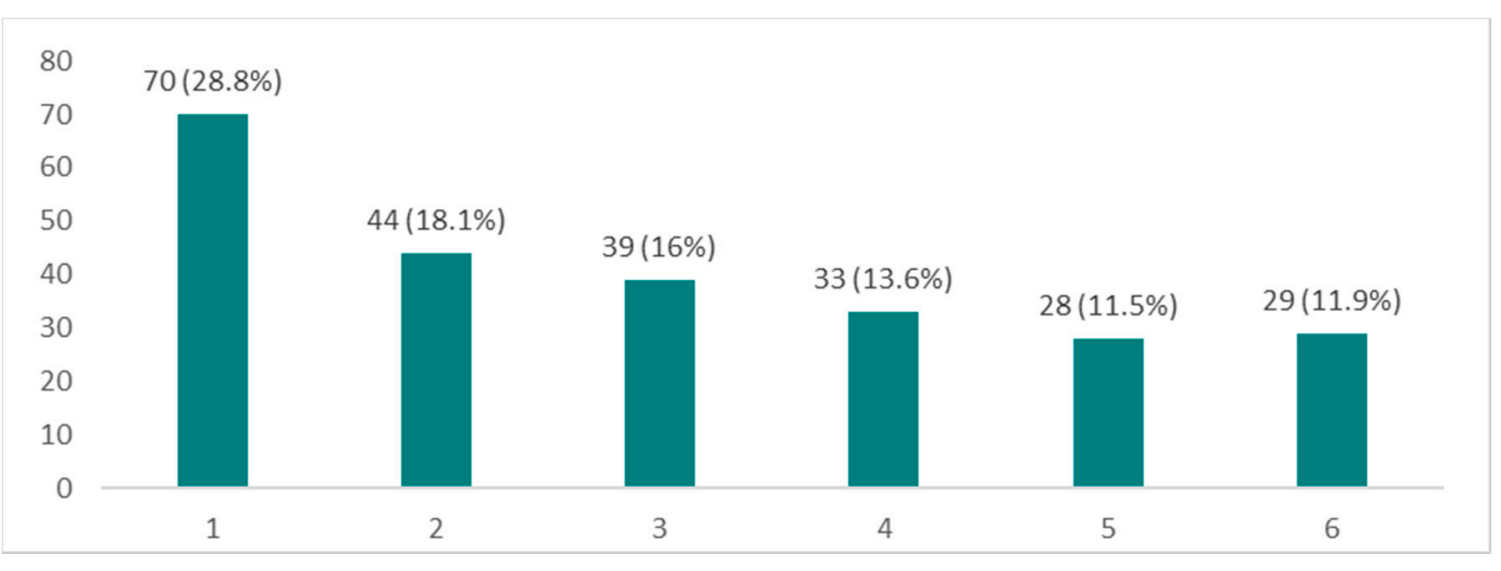

Figure 6. I admit that Covid-19 is a biological weapon manufactured in the laboratory? (1: Totally disagree; 6: Totally agree).

The valid answers, 243, are organized into 153 disagreement responses (63\%) and 90 acceptance responses (37\%). We then sought to verify the existence of an association between acceptance of this theory and the main source that individuals chose to inform themselves about the pandemic (Table 1).

Table 1. Contingency tables of the variables "main source" and "disinformation: biological weapon".

\begin{tabular}{|c|c|c|c|c|c|}
\hline \multicolumn{6}{|c|}{ Main Source * Disinformation: Biological Weapon } \\
\hline & & & \multicolumn{2}{|c|}{ Disinf. Biological Weapon } & \multirow{2}{*}{ Total } \\
\hline & & & Yes & No & \\
\hline \multirow{16}{*}{ Main Source } & \multirow{4}{*}{ TV } & Freq. & 67 & 88 & 155 \\
\hline & & $\%$ Main source & $43.2 \%$ & $56.8 \%$ & $100.0 \%$ \\
\hline & & $\%$ disinf. biological weapon & $74.4 \%$ & $57.5 \%$ & $63.8 \%$ \\
\hline & & $\%$ Total & $27.6 \%$ & $36.2 \%$ & $63.8 \%$ \\
\hline & \multirow{4}{*}{ social networks } & Freq. & 11 & 11 & 22 \\
\hline & & $\%$ Main source & $50.0 \%$ & $50.0 \%$ & $100.0 \%$ \\
\hline & & $\%$ disinf. biological weapon & $12.2 \%$ & $7.2 \%$ & $9.1 \%$ \\
\hline & & $\%$ Total & $4.5 \%$ & $4.5 \%$ & $9.1 \%$ \\
\hline & \multirow{4}{*}{$\begin{array}{c}\text { digital } \\
\text { newspapers }\end{array}$} & Freq. & 7 & 33 & 40 \\
\hline & & $\%$ Main source & $17.5 \%$ & $82.5 \%$ & $100.0 \%$ \\
\hline & & $\%$ disinf. biological weapon & $7.8 \%$ & $21.6 \%$ & $16.5 \%$ \\
\hline & & $\%$ Total & $2.9 \%$ & $13.6 \%$ & $16.5 \%$ \\
\hline & \multirow{4}{*}{$\begin{array}{l}\text { internet } \\
\text { searches }\end{array}$} & Freq. & 4 & 20 & 24 \\
\hline & & $\%$ Main source & $16.7 \%$ & $83.3 \%$ & $100.0 \%$ \\
\hline & & $\%$ disinf. biological weapon & $4.4 \%$ & $13.1 \%$ & $9.9 \%$ \\
\hline & & $\%$ Total & $1.6 \%$ & $8.2 \%$ & $9.9 \%$ \\
\hline
\end{tabular}

Next, we performed the test Chi-squared Pearson for the variables "disinformation: biological weapon" and "main source for information about COVID-19". The results have identified the existence of a significant relationship between the levels of acceptance of that information and the main source used $\left(\chi^{2}(3)=15.093, p=0.05\right)$.

Likewise, the same table of contingencies revealed a greater acceptance of the "conspiracy theory" by individuals who assume as the main source media designated as "accidental", in comparison with those who actively seek information - those who indicate social networks $(50 \%)$ and television $(43 \%)$ have significantly higher levels of misinformation than those who reported digital newspapers $(17.5 \%)$ or Internet searches (16.7). Assuming that a significant level of television consumption has an accidental dimension, these data confirm the thesis stated through the perception "news-finds-me", that the quality 
of information depends on whether individuals actively seek information or are passively informed through accidental exposure.

\section{Conclusions}

We found that most of the results achieved by the present study are consistent with the literature on information consumption in times of uncertainty, as is the case with the current pandemic. From the outset, the obtained data allow us to assume the existence of dependence on the media concerning the need for information from individuals regarding COVID-19, illustrated by widespread consumption, the importance gave to exposure to the informative content conveyed and the diversity of consulted media, in a period marked by social confinement and by the wide reduction of other forms of interaction and direct experience of reality. This confirms our hypothesis that mainstream media are preferred by those looking for information, namely television and digital newspapers. These are also the media that individuals trust most, as advocated by the second hypothesis. The third hypothesis is also confirmed, as it appears that whoever chose conventional media as a source of information demonstrated a lower index of disinformation acceptance. On the contrary, media that are more likely to be accidentally accessed, such as social media and television, have much higher levels of acceptance of false or unconfirmed news about COVID-19. In summary, in times of pandemic, at the beginning of the state of emergency, mostly confined, the individuals questioned consumed information from all available sources (television, social networks, digital newspapers and the Internet), but attributed greater credibility to conventional information media-television and newspapers. Social networks, although regularly consulted, have been trusted by a minority. We can thus suggest the existence of elements that point to digital literacy skills-when verifying the attribution of a hierarchy in information - with journalism obtaining greater credibility compared to that conveyed by social networks.

We point out, in this regard, some limitations of the present study. First, the non-segmentation of content present in social media (where anonymous rumors coexist side by side with publications from mainstream media) and on television (where the diversity of content, information, opinion or entertainment also coexists). Second, social media themselves have developed credible information mechanisms about the pandemic, supported by rigorous information and automatically highlighted in each user's feed. At the same time, they have created mechanisms to scrutinize and report false information, collaborating actively in combating the dangers of infodemic. WHO, for its part, started a dedicated messaging service on WhatsApp and Facebook in Arabic, English, French, Hindi, Italian, Spanish and Portuguese to transmit security and correct information about the pandemic (Sahni and Sharma 2020). The effects of these actions were also not considered by the present study. Finally, the demographic data collected (age and gender) did not make it possible to identify significant differences in the use of the various media, and the confidence attributed to them, so it would be useful to consider other untested variables (education, income, among others). This limitation is highlighted from the results of recent studies (Nielsen et al. 2020), which reveal that people with low levels of formal education have a higher probability of dependence on social media applications to obtain information on the coronavirus, also being more likely to incorrectly answer simple questionnaires about COVID-19.

It is concluded that the dependence on the media, which dates back to the era of mass communication, remains in a situation of a health crisis, although we now live in an ecosystem of informational abundance and that registers the consumption of hybrid media. Despite the use of social networks, it is concluded that citizens continue to maintain confidence in traditional information media regarding access to quality information. Thus, the high consumption of information from all the media, which this study identified, reaffirms the relevance of the theory of media dependence, as a way of obtaining information in contemporary societies, marked by unprecedented levels of media coverage. 
One of the important conclusions of this study was thus that those who actively seek to inform themselves through journalistic mainstream media consider them more reliable-a perception that proves to be adequate, because these citizens demonstrate to be better informed and are less likely to believe in disinformation. It is noted, from here on, a greater danger to citizenship, and that the data of this study confirmed the greater susceptibility to false news by the individuals who attribute greater credibility to the information they find on social media. As shown above, because they satisfy their information needs through social networks, these individuals tend to judge themselves well informed and to do without the consumption of other media. This results in a practical implication: these perceptions point to the importance (and the need) of media literacy actions that provide individuals with mechanisms for assessing the credibility of information sources.

We conclude with a final perception taken from the present study: in a media ecosystem that over the past years has been plagued by progressive crisis of credibility, the current pandemic has shown that journalism continues in what is still its natural place and that the credibility of the media is a very complex issue that needs further investigation. Despite the uncertainty and contradictions associated with it, which this article does not intend to address, we believe that in journalism still resists the ability to fulfill the "vote of confidence" that society has granted it.

Author Contributions: Conceptualization, G.B.F. and S.B.; Methodology, G.B.F. and S.B.; Investigation, G.B.F.; Writing-original draft preparation, G.B.F.; Writing—review and editing, S.B. All authors have read and agreed to the published version of the manuscript.

Funding: This research received no external funding.

Conflicts of Interest: The authors declare no conflict of interest.

\section{References}

Aldrich, John. H., Rachel K. Gibson, Marta Cantijoch, and Tobias Konitzer. 2016. Getting out the vote in the social media era: Are digital tools changing the extent, nature and impact of party contacting in elections? Party Politics 22: 165-78. [CrossRef]

Ball-Rokeach, Sandra J., and Melvin Lawrence DeFleur. 1976. A dependency model of mass media effects. Communication Research 3: 3-21. [CrossRef]

Ball-Rokeach, Sandra J. 1985. The origins of individual media-system dependency: A sociological framework. Communication Research 12: 485-510. [CrossRef]

Barabas, Jason, and Jennifer Jerit. 2009. Estimating the Causal Effects of Media Coverage on Policy-Specific Knowledge. American Journal of Political Science 53: 73-89. [CrossRef]

Bauman, Zygmunt. 2000. Liquid Modernity. London: Polity.

Beck, Ulrich. 1992. Risk Society: Towards a New Modernity. London: Sage.

Bisgin, Halil, Nitin Agarwal, and Xiaowei Xu. 2012. A study of homophily on social media. World Wide Web 15: 213-32. [CrossRef]

Bogaerts, Jo, and Nico Carpentier. 2013. The postmodern challenge to journalism: Strategies for constructing a trustworthy identify. In Rethinking Journalism: Trust and Participation in a Transformed News Landscape. Edited by Chris Peters and Marcel Broersma. London: Routledge, pp. 60-71.

Brennen, J. Scott, Felix Simon, Philip N. Howard, and Rasmus Klein Nielsen. 2020. Types, Sources, and Claims of COVID-19 Misinformation. Reuters Institute for the Study of Journalism. Available online: https: //reutersinstitute.politics.ox.ac.uk/types-sources-and-claims-covid-19-misinformation\#references (accessed on 28 May 2020).

Castells, Manuel. 2007. Communication, Power and Counter-power in the Network Society. International Journal of Communication 1: 238-66.

Cinelli, Mateo, Walter Quattrociocchi, Alessandro Galeazzi, Carlo Michele Valensise, Emanuele Brugnoli, Ana Lucia Schmidt, and Antonio Scala. 2020. The COVID-19 Social Media Infodemic. Available online: https://arxiv.org/pdf/2003.05004.pdf (accessed on 28 May 2020).

Coleman, Stephen. 2012. Believing the news: From sinking trust to atrophied efficacy. European Journal of Communication 27: 35-45. [CrossRef] 
Edelman. 2020. Edelman trust barometer 2020. In Edelman Trust Barometer-Annual Global Study. New York: Edelman.

Fisher, Caroline. 2016. The trouble with 'trust' in news media. Communication Research and Practice 2: 451-65. [CrossRef]

Fuchs, Christian. 2020. Everyday Life and Everyday Communication in Coronavirus Capitalism. tripleC: Communication, Capitalism \& Critique 18: 375-98. [CrossRef]

Glik, Deborah C. 2007. Risk communication for public health emergencies. Annual Review of Public Health 28: 33-54. [CrossRef]

Hermida, Alfred. 2010. Twittering the News the Emergence of Ambient Journalism. Journalism Practice 4: 297-308. [CrossRef]

Hopmann, David Nicolas, Anke Wonneberger, Adam Shehata, and Jonas Höijer. 2016. Selective Media Exposure and Increasing Knowledge Gaps in Swiss Referendum Campaigns. International Journal of Public Opinion Research 28: 73-95. [CrossRef]

Hopmann, David Nicolas, Adam Shehata, and Jesper Strömbäck. 2015. Contagious Media Effects: How Media Use and Exposure to Game-Framed News Influence Media Trust. Mass Communication and Society 18: 776-98. [CrossRef]

$\mathrm{Hu}$, Baijing, and Di Zhang. 2014. Channel selection and knowledge acquisition during the 2009 Beijing H1N1 flu crisis: A media system dependency theory perspective. Chinese Journal of Communication 7: 299-318. [CrossRef]

Jiang, Jing, and Nan Ouyang. 2008. New Media Use During the 5/12 Sichuan Earthquake. Media Asia 35: 148-51. [CrossRef]

Kovach, Bill, and Tom Rosentiel. 2005. Os Elementos do Jornalismo. O que os Profissionais de Jornalismo Devem Saber e o Público Deve Exigir. Porto: Porto Editora.

Longstaff, Pat H. 2005. Security, Resilience, and Communication in Unpredictable Environments Such as Terrorism, Natural Disasters and Complex Technology. Cambridge: Harvard University and the Center for Information Policy Research.

Lowrey, Wilson. 2004. Media Dependency During a Large-Scale Social Disruption: The Case of September 11. Mass Communication and Society 7: 339-57. [CrossRef]

Matsa, Katerina Eva, and Elisa Shearer. 2018. News Use across Social Media Platforms 2018. Washington, DC: Pew Research Center, Available online: http://www.journalism.org/2018/09/10/news-use-across-social-mediaplatforms-2018/ (accessed on 28 May 2020).

Molyneux, Logan. 2018. Mobile news consumption: A habit of snacking. Digital Journalism 6: 634-50. [CrossRef]

Napoli, Philip M. 2019. Social Media and the Public Interest. New York: Columbia University Press. [CrossRef]

Newman, Nic, Richard Fletcher, Antonis Kalogeropoulos, David A. L. Levy, and Rasmus Kleis Nielsen. 2017. Reuters Institute Digital News Report 2017. Oxford: Reuters Institute for the Study of Journalism.

Nielsen, Rasmus Kleis, and Lucas Graves. 2017. News You Don't Believe: Audience Perspectives on Fake News. Oxford: Reuters Institute for the Study of Journalism.

Nielsen, Rasmus Kleis, Richard Fletcher, Nic Newman, J. Scott Brennen, and Philip N. Howard. 2020. Navigating the 'Infodemic': How People in Six Countries Access and Rate News and Information about Coronavirus. Oxford: Reuters Institute for the Study of Journalism.

Prior, Markus. 2005. News vs. Entertainment: How Increasing Media Choice Widens Gaps in Political Knowledge and Turnout. American Journal of Political Science 49: 577-92. [CrossRef]

Sahni, Heena, and Hunny Sharma. 2020. Role of social media during the pandemic COVID-19: Beneficial, destructive, or reconstructive? International Journal of Academic Medicine 6: 70-75. [CrossRef]

Shehata, Adam. 2014. Game Frames, Issue Frames, and Mobilization: Disentangling the Effects of Frame Exposure and Motivated News Attention on Political Cynicism and Engagement. International Journal of Public Opinion Research 26: 157-77. [CrossRef]

Tsfati, Yariv, and Joseph N. Cappella. 2005. Why do people watch news they do not trust? The need for cognition as a moderator in the association between news media skepticism and exposure. Media Psychology 7: 251-71. [CrossRef]

Tsfati, Yariv, and Joseph N. Cappella. 2003. Do people watch what they do not trust? Exploring the association between news media skepticism and exposure. Communication Research 30: 504-29. [CrossRef] 
Wei, Lu, and Douglas Hindman. 2011. Does the digital divide matter more? Comparing the effects of new media and old media use on the education-based knowledge gap. Mass Communication $\mathcal{E}$ Society 14: 216-35. [CrossRef]

World Health Organization. 2020. Infodemic Management: Infodemiology. Available online: https://www.who. int/teams/risk-communication/infodemic-management (accessed on 28 May 2020).

Zúñiga, Homero Gil, and Trevor Diehl. 2019. News finds me perception and democracy: Effects on political knowledge, political interest, and voting. New Media \& Society 21: 1253-71. [CrossRef]

Zúñiga, Homero Gil, Brian Weeks, and Alberto Ardèvol-Abreu. 2017. Effects of the News-Finds-Me Perception in Communication: Social Media Use Implications for News Seeking and Learning About Politics. Journal of Computer-Mediated Communication 22: 105-23. [CrossRef]

Publisher's Note: MDPI stays neutral with regard to jurisdictional claims in published maps and institutional affiliations.

(C) 2020 by the authors. Licensee MDPI, Basel, Switzerland. This article is an open access article distributed under the terms and conditions of the Creative Commons Attribution (CC BY) license (http://creativecommons.org/licenses/by/4.0/). 